\title{
Optimal Speed Profile Determination with Fixed Trip Time in the Electric Train Operation of the Cat Linh- Ha Dong Metro Line based on Pontryagin's Maximum Principle
}

\author{
An Thi Hoai Thu Anh \\ Department of Electrical Engineering \\ University of Transport and Communications \\ Hanoi, Vietnam \\ htanh.ktd@utc.edu.vn
}

\author{
Nguyen Van Quyen \\ Department of Applied Mechanics \\ Hanoi University of Science and Technology \\ Hanoi, Vietnam \\ quyen.nguyenvan@hust.edu.vn
}

\begin{abstract}
The significant energy consumption for railway electric transportation operation poses a great challenge in outlining saving energy solutions. Speed profile optimization based on optimal control theory is one of the most common methods to improve energy efficiency without the railway infrastructure investment costs. The paper proposes an optimization method based on Pontryagin's Maximum Principle (PMP), not only to find optimal switching points in three operation phases: accelerating, coasting, braking, and from these switching points being able to determine the optimal speed profile, but also to ensure fixed-trip time. In order to determine trip time abiding by the scheduled timetables by applying nonlinear programming puts the Lagrange multiplier $\lambda$ in the objective function regarded as a time constraint condition. The correctness and energy effectiveness of this method have been verified by the simulation results with data collected from the electrified trains of the Cat Linh-Ha Dong metro line in Vietnam. The saving energy levels are compared in three scenarios: electrified train operation tracking the original speed profile (energy consumption of the route: $144.64 \mathrm{kWh}$ ), train operation tracking the optimal speed profile without fixed-trip time (energy consumption of the route: $129.18 \mathrm{kWh}$ ), and train operation tracking the optimal speed profile and fixed trip time (energy consumption of the route: $132.99 \mathrm{kWh}$ ) in an effort to give some useful choices for operating metro lines.
\end{abstract}

Keywords-metro system; energy-saving; energy-efficient operation methodology; timetable optimization

\section{INTRODUCTION}

With the worldwide booming of urbanization, people face the increased carbon emission problem and the traffic congestion to affect their quality of live. Under these circumstances, the urban railway systems play a key role in removing the harmful effects of urban mobility due to their advantages such as large passenger capacity, safety, and less environmental pollution $[1,2]$. Metro lines in the big cities of Vietnam are under construction or expansion with a total rout length of about $500 \mathrm{~km}$. However, the traction system of metro trains consumes a huge proportion of energy [3], so it is vital to find some solutions to minimize the total energy consumption of the railway transportation system.

Among numerous energy saving solutions, speed profile optimization which reduces energy consumption without investing into infrastructure has attracted attention. There are two known methods of speed optimization: the Mathematical and Optimal theory and Computational Intelligence [4]. Authors in [5-9] systematically researched optimal strategies using mathematical approaches and the Optimal theory to propose control laws to detect the optimal switching points and to find the optimal speed profile whereas authors in [10] attempted to solve the problem of optimal control by applying the Pontryagin's Maximum Principle (PMP). Authors in [11] used PMP to find a set of optimal controls, the control switching graphs, and complementary conditions of optimality. Authors in [12] applied three optimization algorithms (Colony Optimization Algorithm, Dynamic Programming, Genetic Algorithm (GA)) to search for the optimal speed trajectory, while authors in [13] applied the Ant Colony Algorithm to find an optimal power profile to save energy. Authors in [14] designed the speed profile giving guarantees of running time and saving energy consumption. Authors in [15] designed the train operation speed profiles for an Automatic Train Operation System (ATO) to select the optimal speed profiles with reduced energy consumption. Authors in [16] designed a Decentralized Train Traffic Management System (DTMS) which not only possessed good Automatic Train Control (ATC) operation, but also saved a significant amount of running time. Authors in [17] used GA and authors in [18] utilized Artificial Neural Networks (ANNs) and GA to determine the optimal coasting point. Authors in [19] dealt with speed profile optimization using Pontryagin's Maximum Principle (PMP) and achieved energy-saving but did not guarantee fixed running time in the Cat Linh - Ha Dong metro line in Vietnam.

In this paper, PMP is also chosen to determine optimal speed profile, and also ensure fixed trip time thanks to the 
Lagrange multiplier $\lambda$ being put into the objective function regarding the Cat Linh - Ha Dong metro line. The simulation results with three diffirent seniories showed the effectiveness of PMP optimal control method in saving energy of train operation without any changes of infrustructure or facilities.

\section{MOTION MODEL OF THE TRAIN}

The train is regarded as a particle and kinematic equation that can be represented by the following continuous - space model [20, 21]:

$$
\left\{\begin{array}{l}
\frac{d x}{d t}=v \\
m v \frac{d v}{d x}=F_{t r}(v)-F_{b r}(v)-W_{0}(v)-F_{g r a d}(x)
\end{array}\right.
$$

where $v, t, x, m$ represent train speed $(\mathrm{m} / \mathrm{s})$, operation time (s), train position $(\mathrm{m})$, full load translating mass of train (tones) and $F_{t r}, F_{b r}, W_{0}, F_{\text {grad }}$ are traction, electrical braking, resistance, and gradient resistance forces applied on the train.

Based on the curves of $F_{t r}$ and $F_{b r}$ given by the manufacturers [21], the least square method is utilized to find the equivalent polynomials. The maximum traction and maximum braking forces corresponding to the speed $v$ are:

$$
\begin{aligned}
& F_{t r}= \begin{cases}13.2 & (0 \leq v \leq 32) \\
-2.5 \cdot 10^{-5} v^{3}+0.007 \cdot v^{2} & (32<v \leq 80) \\
-0.66 v+28.35 & (0 \leq v \leq 65)\end{cases} \\
& F_{b r}= \begin{cases}14.7 & (65<v \leq 75) \\
-0.254 v+31.21 & (75<v \leq 80) \\
-0.2027 v+27.36 & \end{cases}
\end{aligned}
$$

The forces acting on the train in which the resistance force comprises of the air resistance, the friction resistance can be seen in [21]. The basic resistance $w_{0}$ can be calculated by the Davis formula [22]:

$$
w_{0}=\frac{W_{0}}{m}=a+b v+c v^{2}
$$

where $a, b, c$ are the coefficients of train resistances.

The gradient force $F_{\text {grad }}$ caused by the slope of the road is:

$$
F_{\text {grad }}=m g \sin \alpha
$$

where $g, \alpha$ are the gravity acceleration and the rail track slope respectively.

\section{SPEED PROFILE OPTIMALITY ANALYSIS BASED ON PMP AND ENERGY CONSUMPTION}

Depending on the distance between stations, a train operates in three or four phases. For short distances, the train runs in three phases: accelerating, coasting, and braking. Forces acting on a train in operation modes are different. The tractive force acts during the accelerating and cruising processes, the basic resistance force acts during all processes, while the braking force acts during the breaking process.

\section{A. Problem Formulation}

The motion of a train along a track can be rewritten by the state equations:

$$
\left\{\begin{array}{l}
\frac{d t}{d x}=\frac{1}{v} \\
v \frac{d v}{d x}=u_{t r} f_{t r}(v)-u_{b r} f_{b r}(v)-w_{0}(v)-f_{g r a d}(x)
\end{array}\right.
$$

where $u_{t r}, u_{b r}$ are the defined traction and braking control variables of train, both of which are restrained by: $u_{t r} \in[0,1]$, $u_{b r} \in[0,1]$, and $f_{t r}, f_{b r}, f_{\text {grad }}$ are the traction force applied at the wheels, the braking force, and the gradient force acting on the train. Therefore, the boundary conditions are given by:

$$
\left\{\begin{array}{l}
v(0)=0, v(X)=0, t(0)=0 \\
0 \leq v(x) \leq V(x), 0 \leq t(X) \leq T, 0 \leq x \leq X
\end{array}\right.
$$

where $V(x)$ is the maximum allowable speed, $X$ is the terminal of the train operation, $v(0), v(X)$ are the speed at the beginning and at the end of the route, $T$ is the duration of the trip which is also given by the timetable.

The objective is to minimize the train's operation energy consumption as the train runs from location $x=0$ to $x=X$ in time $T$ by controlling the traction force, while ignoring electric braking force since regenerative braking energy is not recovered. The objective function is written as:

$$
J=\int_{0}^{X}\left[u_{t r} f_{t r}(v)\right] d x+\lambda T \rightarrow \min
$$

where $T=T_{\text {actual }}(X)-T_{\text {demand }}(X)$, and $\lambda$ is an unknown Lagrange multiplier. Given:

$$
T_{\text {actual }}(x)=\int_{0}^{X} \frac{d x}{v}
$$

Finding the value of the Lagrange multiplier is to deliver the required running time $T_{\text {demand }}(X)$, while $T_{\text {actual }}$ is the actual running time of the train. Therefore the objective function is:

$$
J=\int_{0}^{X}\left[u_{t r} f_{t r}(v)+\frac{\lambda}{v}\right] d x \rightarrow \min
$$

\section{B. Solution}

To find the optimal solutions of an objective function by PMP is equivalent to maximize its Hamiltonian equation. Based on (6), (8), a Hamilton function is formed as: 


$$
\begin{aligned}
H & =-u_{t r} f_{t r}(v)-\frac{\lambda}{v}+p_{1} \frac{1}{v} \\
& +p_{2}\left(\frac{u_{t r} f_{t r}(v)-u_{b r} f_{b r}(v)-w_{0}(v)-f_{g r a d}(x)}{v}\right)
\end{aligned}
$$

where $p_{1}, p_{2}$ are adjoint variables.

The adjoint variable differential equations are reformed:

$$
\begin{gathered}
\frac{d p_{1}}{d x}=-\frac{\partial H}{\partial t}=0 \\
\frac{d p_{2}}{d x}=-\frac{\partial H}{\partial v}=u_{t r} \frac{\partial f_{t r}}{\partial v}-\frac{\lambda}{v^{2}}+p_{1} \frac{1}{v^{2}} \\
+\frac{p_{2}}{v^{2}}\left[u_{t r} f_{t r}(v)-u_{b r} f_{b r}(v)-w_{0}(v)-f_{g r a d}(x)\right] \\
-\frac{p_{2}}{v}\left[u_{t r} \frac{\partial f_{t r}}{\partial v}-u_{b r} \frac{\partial f_{b r}}{\partial v}-\frac{\partial w_{0}}{\partial v}\right]
\end{gathered}
$$

Defining:

$$
p=\frac{p_{2}}{v}, \text { so } \frac{d p}{d x}=\frac{1}{v}\left(\frac{d p_{2}}{d x}-p \frac{d v}{d x}\right)
$$

Given:

$$
\frac{d v}{d x}=\frac{u_{t r} f_{t r}(v)-u_{b r} f_{b r}(v)-w_{0}(v)-f_{g r a d}(x)}{v}
$$

We get:

$$
H=(p-1) u_{t r} f_{t r}-p u_{b r} f_{b r}-p\left(w_{0}+f_{g r a d}\right)-\frac{\lambda}{v}+\frac{p_{1}}{v}
$$

The Hamiltonian function is maximized by the following values of $u_{t r}$ and $u_{b r}[19]$ :

$$
\left\{\begin{array} { l l l } 
{ u _ { t r } = 1 } & { \text { if } } & { p > 1 } \\
{ u _ { t r } \in ( 0 , 1 ) } & { \text { if } } & { p = 1 \text { and } } \\
{ u _ { t r } = 0 } & { \text { if } } & { p < 1 }
\end{array} \left\{\begin{array}{lll}
u_{b r}=0 & \text { if } & 0<p<1 \\
u_{b r} \in(0,1) & \text { if } & p=0 \\
u_{b r}=1 & \text { if } & p<0
\end{array}\right.\right.
$$

From the above analysis, five optimal control laws are designed:

- Full power (FP): $u_{t r}=1, u_{b r}=0$ when $p>1$

- Partial power (PP): $u_{t r} \in[0,1], u_{b r}=0$ when $p=1$

- Coasting (C): $u_{t r}=0, u_{b r}=0$ when $0<p<1$

- Full braking (FB): $u_{t r}=0, u_{b r}=1$ when $p<0$

- Partial braking (PB): $u_{t r}=0, u_{b r} \in[0,1]$ when $p=0$

Substituting (13) and (15) in (14) leads to finding the differential equation for $p(x)$ :

$$
\frac{d p}{d x}=\frac{(1-p)}{v} u_{t r} f_{t r}^{\prime}(v)+\frac{p}{v} u_{b r} f_{b r}^{\prime}(v)+\frac{p}{v} w_{0}^{\prime}(v)-\frac{\lambda}{v^{3}}-\frac{p_{1}}{v^{3}}
$$

From (12), $p_{1}$ is easily chosen to be 0 .

\section{1) Full Power Mode}

With $p>1, u_{b r}=0, u_{t r}=1$, finding accelerating time $t_{a}$ and accelerating distance $x_{a}$ can be done by using (18). We get:

$$
\frac{d p}{d x}=\frac{(1-p)}{v} f_{t r}^{\prime}(v)+\frac{p}{v} w_{0}^{\prime}(v)-\frac{\lambda}{v^{3}}-\frac{p_{1}}{v^{3}}
$$

From (6) we find the differential equations to determine $x_{a}, t_{a}:$

$$
\left\{\begin{array}{l}
\frac{d x}{d v}=\frac{v}{u_{t r} f_{t r}(v)-w_{0}(v)-f_{\text {grad }}(x)} \\
\frac{d t}{d v}=-\frac{1}{u_{t r} f_{t r}(v)-w_{0}(v)-f_{\text {grad }}(x)}
\end{array}\right.
$$

With initial conditions: $x(0)=0, t(0)=0$.

\section{2) Partial Power Mode}

With $p=1, u_{b r}=0,0<u_{t r}<1$ and using equation:

$$
\frac{1}{v} w_{0}^{\prime}(v)-\frac{\lambda}{v^{3}}-\frac{p_{1}}{v^{3}}=0
$$

where $v_{h}$-hold speed is chosen previously and $p_{1}$ is 0 , we get:

$$
\lambda=v^{2} w_{0}^{\prime}
$$

therefore:

$$
\lambda=v^{2}(b+2 c v)
$$

If $\lambda$ is chosen previously, we can solve (23) to find the hold-speed $v_{h}$

\section{3) Coasting Mode}

The conditions $u_{t r}=0, u_{b r}=0,0<p<1$ are applied. The coasting speed $v_{b}$ is calculated as $[4,23]$ :

$$
v_{b}=\frac{\psi\left(v_{h}\right)}{\varphi^{\prime}\left(v_{h}\right)}
$$

where $\varphi=v \cdot w_{0}(v), \psi=v^{2} \cdot w_{0}^{\prime}(v)$.

From (6) we find the differential equations to determine $x_{c}, t_{c}:$ 


$$
\left\{\begin{array}{l}
\frac{d x}{d v}=\frac{v}{-w_{0}(v)-f_{\text {grad }}(x)} \\
\frac{d t}{d v}=-\frac{1}{w_{0}(v)+f_{\text {grad }}(x)}
\end{array}\right.
$$

with $t\left(v=v_{h}\right)=t_{a} ; x\left(v=v_{h}\right)=x_{a}$.

\section{4) Full Braking Mode}

The conditions $u_{t r}=0, u_{b r}=1, p<0$ are applied. Using (18) we can find braking time and braking distance:

$$
\frac{d p}{d x}=\frac{p}{v} f_{b r}^{\prime}(v)+\frac{p}{v} w_{0}^{\prime}(v)-\frac{\lambda}{v^{3}}-\frac{p_{1}}{v^{3}}
$$

From (6) we get the differential equations:

$$
\left\{\begin{array}{l}
\frac{d x}{d v}=\frac{v^{2}}{-v \cdot u_{b r} f_{b r}(v)-v \cdot w_{0}(v)+p_{s c}(t)-v \cdot f_{g r a d}(x)} \\
\frac{d t}{d v}=\frac{1}{u_{b r} f_{b r}(v)-w_{0}(v)+\frac{p_{s c}(t)}{v}-f_{g r a d}(x)}
\end{array}\right.
$$

with $t\left(v=v_{b}\right)=t_{b}, x\left(v=v_{b}\right)=x_{b}$.

\section{SIMULATION RESULTS COMPARISON FOR VARIOUS SCENARIOS}

The simulations are based on the data of Cat Linh-Ha Dong metro line. There are 12 stations, 1 depot, and 6 traction substations. The simulation results are performed for the first Cat Linh station to the 12th Yen Nghia station in a route which is $13 \mathrm{~km}$ in length [18]. The full load translating mass is 246.7 ton and 8 electrical traction motors are used. David's coefficients of train's resistance are: $a=1.19 \cdot 10^{-2}$, $b=2.56 \cdot 10^{-3}, c=1.54 \cdot 10^{-4}$. Assessing the levels of energy savings follow 3 scenarios: energy consumption with original speed profile with fixed trip time, energy consumption with optimal speed profile with fixed trip time, and energy consumption with optimal speed profile but with trip time which is less by $1 \mathrm{~s}$ in each station. The goal of different simulation scenarios is to give diversified operation choices regarding energy saving for different metro lines.

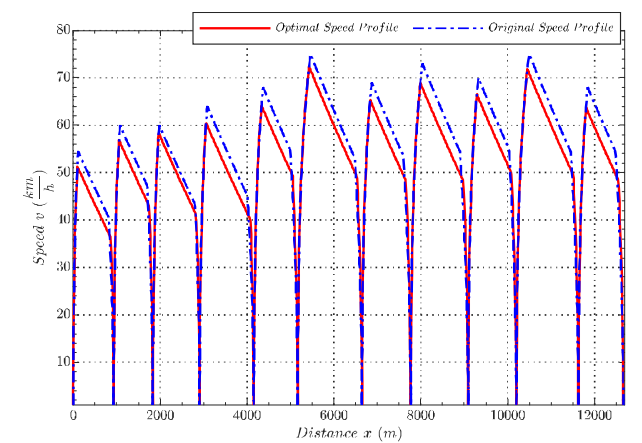

Fig. 1. Comparison of optimal and original speed profile without fixedtrip time.
The results and their comparison for the optimal speed profile and the original speed profile vs distance without fixedtrip time can be seen in Figure 1. The results and their comparison for the optimal and original time profile vs distance without fixed-trip time can be seen in Figure 2. The results and their comparison for optimal and original speed profile vs distance with fixed-trip time can be seen in Figure 3 and for optimal and original time profile vs distance with fixed-trip time can be seen in Figure 4.

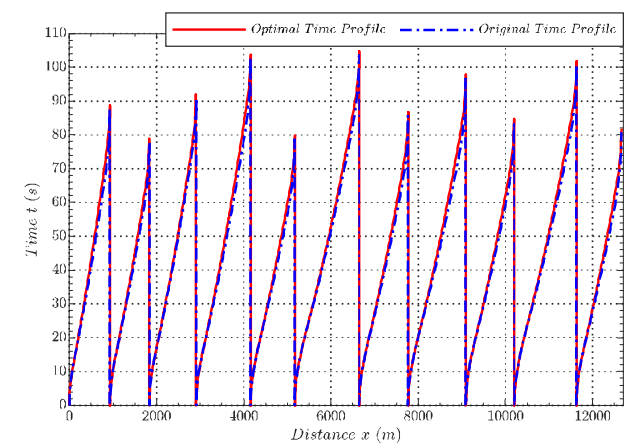

Fig. 2. Comparison of optimal original time profile without fixed-trip time.

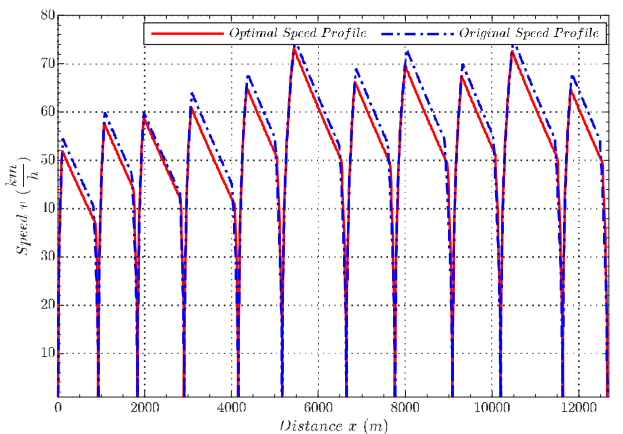

Fig. 3. Comparison of optimal and original speed profile with fixed-trip time.

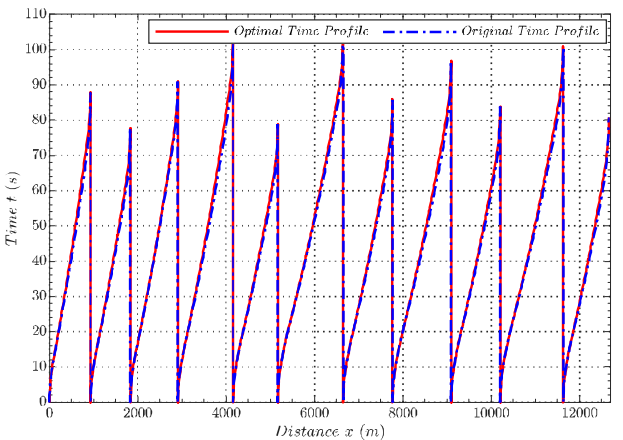

Fig. 4. Comparison of optimal original time profile with fixed-trip time.

Regarding track conditions and constraints, the speed from a station to another station is different: the slowest speed is $53 \mathrm{~km} / \mathrm{h}$ and the highest is $73 \mathrm{~km} / \mathrm{h}$, which means that the speed is always lower than the limit of $80 \mathrm{~km} / \mathrm{h}$. The optimal trip time is longer approximately by $1 \mathrm{~s}$. It was also shown that along with optimal switching points change, so do the optimal 
accelerating, coasting, and braking distances. Table I demonstrates that the percentage of total energy saving is up to $11.96 \%$ (practical energy consumption is $144.64 \mathrm{kWh}$, while optimal energy consumption obtains $129.18 \mathrm{kWh}$ ).

TABLE I. COMPARISON RESULTS OF THE ENERGY CONSUMPTION WITH NON-FIXED TRIP TIME

\begin{tabular}{|c|c|c|c|c|c|c|}
\hline $\begin{array}{c}\text { Inter-station } \\
\text { length }\end{array}$ & $\begin{array}{c}\text { Distance } \\
\text { (m) }\end{array}$ & $\begin{array}{c}\text { Original } \\
\text { trip } \\
\text { time (s) }\end{array}$ & $\begin{array}{c}\text { Practical } \\
\text { energy } \\
\text { consumption } \\
\text { (kWh) }\end{array}$ & $\begin{array}{c}\text { Optimal } \\
\text { trip time } \\
\text { (s) }\end{array}$ & $\begin{array}{c}\text { Optimal } \\
\text { energy } \\
\text { consumption } \\
\text { (kWh) }\end{array}$ & $\begin{array}{c}\text { Energy } \\
\text { saving } \\
\text { (\%) }\end{array}$ \\
\hline $\begin{array}{c}\text { Cat Linh-La } \\
\text { Thanh }\end{array}$ & 931 & 88 & 8.31 & 88.81 & 7.31 & 13.68 \\
\hline $\begin{array}{c}\text { La Thanh- } \\
\text { Thai Ha }\end{array}$ & 902 & 78 & 10.20 & 78.83 & 9.08 & 12.33 \\
\hline $\begin{array}{c}\text { Thai Ha- } \\
\text { Lang }\end{array}$ & 1076 & 91 & 10.20 & 91.85 & 9.60 & 6.25 \\
\hline Lang-VNU & 1248 & 103 & 11.73 & 103.82 & 10.37 & 13.11 \\
\hline $\begin{array}{c}\text { VNU- Ring } \\
\text { Road 3 }\end{array}$ & 1010 & 79 & 13.41 & 79.8 & 11.78 & 13.84 \\
\hline $\begin{array}{c}\text { Ring Road 3- } \\
\text { Thanh Xuan }\end{array}$ & 1480 & 104 & 16.75 & 104.85 & 15.44 & 8.48 \\
\hline $\begin{array}{c}\text { Thanh Xuan- } \\
\text { Ha Dong BS }\end{array}$ & 1121 & 86 & 13.85 & 86.82 & 12.26 & 12.97 \\
\hline $\begin{array}{c}\text { Ha Dong BS- } \\
\text { BV Ha Dong }\end{array}$ & 1324 & 97 & 15.74 & 97.83 & 13.80 & 14.06 \\
\hline $\begin{array}{c}\text { BV Ha } \\
\text { Dong-La } \\
\text { Khe }\end{array}$ & 1110 & 84 & 14.30 & 84.77 & 12.77 & 11.98 \\
\hline $\begin{array}{c}\text { La Khe-Van } \\
\text { Khe }\end{array}$ & 1428 & 101 & 16.75 & 101.86 & 15.15 & 10.56 \\
\hline $\begin{array}{c}\text { Van Khe- } \\
\text { Yen Nghia }\end{array}$ & 1032 & 81 & 13.40 & 81.82 & 11.62 & 15.32 \\
\hline $\begin{array}{c}\text { Total energy } \\
\text { consumption }\end{array}$ & 144.64 & 129.18 & $\mathbf{1 1 . 9 6}$ \\
\hline
\end{tabular}

TABLE II. COMPARISON RESULTS OF THE ENERGY CONSUMPTION WITH FIXED-TRIP TIME

\begin{tabular}{|c|c|c|c|c|c|}
\hline $\begin{array}{c}\text { Inter-station } \\
\text { length }\end{array}$ & $\begin{array}{c}\text { Distance } \\
\text { (m) }\end{array}$ & $\begin{array}{c}\text { Trip } \\
\text { time } \\
\text { (s) }\end{array}$ & $\begin{array}{c}\text { Practical energy } \\
\text { consumption } \\
\text { (kWh) }\end{array}$ & $\begin{array}{c}\text { Optimal energy } \\
\text { consumption } \\
\text { (kWh) }\end{array}$ & $\begin{array}{c}\text { Energy } \\
\text { saving } \\
\mathbf{( \% )}\end{array}$ \\
\hline $\begin{array}{c}\text { Cat Linh-La } \\
\text { Thanh }\end{array}$ & 931 & 88 & 8.31 & 7.50 & 9.75 \\
\hline $\begin{array}{c}\text { La Thanh-Thai } \\
\text { Ha }\end{array}$ & 902 & 78 & 10.20 & 9.40 & 7.84 \\
\hline Thai Ha-Lang & 1076 & 91 & 10.20 & 9.86 & 3.33 \\
\hline Lang-VNU & 1248 & 103 & 11.73 & 10.60 & 9.63 \\
\hline $\begin{array}{c}\text { VNU- Ring } \\
\text { Road 3 }\end{array}$ & 1010 & 79 & 13.41 & 12.23 & 8.80 \\
\hline $\begin{array}{c}\text { Ring Road 3- } \\
\text { Thanh Xuan }\end{array}$ & 1480 & 104 & 16.75 & 15.82 & 5.55 \\
\hline $\begin{array}{c}\text { Thanh Xuan- } \\
\text { Ha Dong BS }\end{array}$ & 1121 & 86 & 13.85 & 12.66 & 8.59 \\
\hline $\begin{array}{c}\text { Ha Dong BS- } \\
\text { BV Ha Dong }\end{array}$ & 1324 & 97 & 15.74 & 14.17 & 9.97 \\
\hline $\begin{array}{c}\text { BV Ha Dong- } \\
\text { La Khe }\end{array}$ & 1110 & 84 & 14.30 & 13.18 & 7.83 \\
\hline $\begin{array}{c}\text { La Khe-Van } \\
\text { Khe }\end{array}$ & 1428 & 101 & 16.75 & 15.53 & 7.28 \\
\hline $\begin{array}{c}\text { Van Khe-Yen } \\
\text { Nghia }\end{array}$ & 1032 & 81 & 13.40 & 12.04 & 10.15 \\
\hline $\begin{array}{c}\text { Total energy } \\
\text { consumption }\end{array}$ & & $\mathbf{1 4 4 . 6 4}$ & $\mathbf{1 3 2 . 9 9}$ & $\mathbf{8 . 7}$ \\
\hline
\end{tabular}

Figures 3, 4 and Table II indicate that the optimal speed profile with fixed running time complied with the scheduled timetable and the saving energy level is $8.7 \%$ (the practical energy consumption is $144.64 \mathrm{kWh}$, while the optimal energy consumption is $132.99 \mathrm{kWh}$ ).

\section{CONCLUSION}

The simulation results by applying PMP to find the optimal speed profile with and without fixed trip time for the 12 stations of the Cat Linh - Ha Dong metro line operating in three phases (accelerating, coasting, and braking) showed a saving energy percentage varying from $8.7 \%$ to $11.96 \%$ in comparison with the original speed profile. This research contributes to the modes of ATO. If the metro line is going to conduct surveys on the train timetable, it may be able to choose the optimal speed profile with longer trip time, and reduce the dwelling time because this speed profile saves energy to a level up to $11.96 \%$. If the metro lines are in operation, the optimal speed profile with fixed trip time should be chosen as the second scenario with a saving energy level of about $8.7 \%$.

\section{ACKNOWLEDGEMENT}

The authors would like to thank the University of Transport and Communications (UTC) for funding this research and the Institute for Control and Automation creates for providing the research facilities.

\section{REFERENCES}

[1] G. R. Kazemiyan, A. Rasooli, and S. Rafipoor, "The advantages of rail transport compared to road within the city, based on a sustainable development approach, case study Tehran Metro Line 4," Research and Urban Planning, vol. 6, no. 23, pp. 77-94, Jan. 2016.

[2] V. R. Vuchic, Urban Transit Systems and Technology, 1st ed. Hoboken, NJ, USA: Wiley, 2007.

[3] S. Su, T. Tang, and Y. Wang, "Evaluation of Strategies to Reducing Traction Energy Consumption of Metro Systems Using an Optimal Train Control Simulation Model," Energies, vol. 9, no. 2, p. 105, Feb. 2016, https://doi.org/10.3390/en9020105.

[4] J. Yang, L. Jia, S. Lu, Y. Fu, and J. Ge, "Energy-Efficient Speed Profile Approximation: An Optimal Switching Region-Based Approach with Adaptive Resolution," Energies, vol. 9, no. 10, pp. 1-27, 2016.

[5] P. Howlett, "The Optimal Control of a Train," Annals of Operations Research, vol. 98, no. 1, pp. 65-87, Dec. 2000, https://doi.org/10.1023/ A: 1019235819716.

[6] P. G. Howlett and P. J. Pudney, Energy-Efficient Train Control. London, UK: Springer-Verlag, 1995.

[7] X. Vu, Analysis of necessary conditions for the optimal control of a train: New neccessary conditions for energy-efficient train control. VDM Verlag Dr. Müller, 2009.

[8] A. Albrecht, P. Howlett, P. Pudney, X. Vu, and P. Zhou, "The key principles of optimal train control-Part 1: Formulation of the model, strategies of optimal type, evolutionary lines, location of optimal switching points," Transportation Research Part B: Methodological, vol. 94, pp. 482-508, Dec. 2016, https://doi.org/10.1016/ j.trb.2015.07.023.

[9] A. Albrecht, P. Howlett, P. Pudney, X. Vu, and P. Zhou, "The key principles of optimal train control-Part 2: Existence of an optimal strategy, the local energy minimization principle, uniqueness, computational techniques," Transportation Research Part B: Methodological, vol. 94, pp. 509-538, Dec. 2016, https://doi.org/ 10.1016/j.trb.2015.07.024.

[10] E. Khmelnitsky, "On an optimal control problem of train operation," IEEE Transactions on Automatic Control, vol. 45, no. 7, pp. 1257-1266, Jul. 2000, https://doi.org/10.1109/9.867018.

[11] R. Liu and I. M. Golovitcher, "Energy-efficient operation of rail vehicles," Transportation Research Part A: Policy and Practice, vol. 37, 
no. 10, pp. 917-932, Dec. 2003, https://doi.org/10.1016/j.tra.2003. 07.001 .

[12] S. Lu, S. Hillmansen, T. K. Ho, and C. Roberts, "Single-Train Trajectory Optimization," IEEE Transactions on Intelligent Transportation Systems, vol. 14, no. 2, pp. 743-750, Jun. 2013, https://doi.org/ 10.1109/TITS.2012.2234118.

[13] H. Ehteshami, S. Javadi, and S. M. Shariatmadar, "Improving the Power Quality in Tehran Metro Line-Two Using the Ant Colony Algorithm," Engineering, Technology \& Applied Science Research, vol. 7, no. 6, pp. 2256-2259, Dec. 2017, https://doi.org/10.48084/etasr.1551.

[14] M. Domínguez, A. Fernández, A. P. Cucala, and L. P. Cayuela, "Computer-aided design of ATO speed commands according to energy consumption criteria," presented at the COMPRAIL 2008, Toledo, Spain, Aug. 2008, pp. 183-192, https://doi.org/10.2495/CR080191.

[15] M. Domínguez, A. Fernández, A. P. Cucala, and P. Lukaszewicz, "Optimal design of metro automatic train operation speed profiles for reducing energy consumption," Proceedings of the Institution of Mechanical Engineers, Part F: Journal of Rail and Rapid Transit, Aug. 2011, https://doi.org/10.1177/09544097JRRT420.

[16] T. Kara and M. C. Savas, "Design and Simulation of a Decentralized Railway Traffic Control System," Engineering, Technology \& Applied Science Research, vol. 6, no. 2, pp. 945-951, Apr. 2016, https://doi.org/10.48084/etasr.631.

[17] K. K. Wong and T. K. Ho, "Dynamic coast control of train movement with genetic algorithm," International Journal of Systems Science, vol. 35, no. 13-14, pp. 835-846, Oct. 2004, https://doi.org/10.1080/ 00207720412331203633.

[18] S. Acikbas and M. T. Soylemez, "Coasting point optimisation for mass rail transit lines using artificial neural networks and genetic algorithms," IET Electric Power Applications, vol. 2, no. 3, pp. 172-182, May 2008, https://doi.org/10.1049/iet-epa:20070381.

[19] A. T. H. T. Anh, N. V. Quyen, N. T. Hai, N. V. Lien, and V. H. Phuong, "Speed profile optimization of an electrified train in Cat Linh-Ha Dong metro line based on pontryagin's maximum principle," International Journal of Electrical and Computer Engineering (IJECE), vol. 10, no. 1, pp. 233-242, Feb. 2020, https://doi.org/10.11591/ijece.v10i1.pp233-242.

[20] X. Sun, H. Lu, and H. Dong, "Energy-Efficient Train Control by MultiTrain Dynamic Cooperation," IEEE Transactions on Intelligent Transportation Systems, vol. 18, no. 11, pp. 3114-3121, Nov. 2017, https://doi.org/10.1109/TITS.2017.2682270.

[21] N. T. M. Chau, Hanoi Urban Railway Project Cat Linh-Ha Dong Line. Package 1: EPC Contact. Technical Design, Book 2: Traffic organization and operation management. Hanoi, Vietnam: Railway Project Management Unit, Vietnam Railway Administration, 2014.

[22] W. Davis, The tractive resistance of electric locomotives and cars. General Electric, 1926.

[23] N. T. Hai, "Evaluation of effect Pontryagin's Maximum Principle for optimal control train by criteria of energy save," in 2010 International Symposium on Computer, Communication, Control and Automation (3CA), Tainan, Taiwan, May 2010, vol. 1, pp. 363-366, https://doi.org/10.1109/3CA.2010.5533807. 